\title{
Quantifying passive myocardial stiffness and wall stress in heart failure patients using personalized ventricular mechanics
}

\author{
Zhinuo Jenny Wang ${ }^{1 *}$, Vicky Y Wang ${ }^{1}$, Chris P Bradley ${ }^{1}$, Martyn P Nash ${ }^{1,2}$, Alistair Young ${ }^{1,4}$, Jie J Cao ${ }^{3}$ \\ From 19th Annual SCMR Scientific Sessions \\ Los Angeles, CA, USA. 27-30 January 2016
}

\section{Background}

Heart failure (HF) patients present with a spectrum of phenotypes, including preserved ejection fraction (HFpEF) and reduced $\mathrm{EF}$ (HFrEF). The underlying mechanisms of HFpEF and HFrEF may be related to mechanical factors such as stiffness and stress. This study aimed to quantify passive mechanical properties in HFrEF and HFpEF patients using personalised left ventricular (LV) biomechanical analysis.

\section{Methods}

Data from 9 HFrEF patients, 4 HFpEF patients, and 4 nonHF patients with normal LV function (control) were analyzed. LV finite element mechanical models were personalized using LV surface data segmented from cine cardiac magnetic resonance (CMR) images. All subjects underwent same day left and right cardiac catheterization. Beat-averaged intra-ventricular pressures were extracted from LV catheter traces and temporally aligned with the CMR images. A mechanical simulation of LV diastolic filling was optimized to each patient-specific geometry and pressure loading, incorporating non-linear myocardial ani- sotropic tissue behavior and myocyte fiber orientation derived from our published work. Global myocardial passive stiffness was estimated by optimization of the predicted LV surface displacements between diastasis and end-diastole to the observed CMR motion. Mid-ventricular end-diastolic fiber stress was also derived from the model.

\section{Results}

Volume and pressure changes between diastasis and end-diastole, and LV mass measurements are shown in Table 1 (mass and volume data have been normalised by body surface area). Myocardial stiffness was significantly higher for the HFrEF group (mean \pm SEM $7.6 \pm$ $1.6 \mathrm{kPa})$ compared to both the control group $(1.3 \pm 0.3$ $\mathrm{kPa}, \mathrm{p}<0.01)$, and the HFpEF group $(2.1 \pm 0.4 \mathrm{kPa}, \mathrm{p}<$ 0.01 ), but no significant difference was found between control and HFpEF groups due to small sample sizes. Mid-ventricular end-diastolic fiber stress was also significantly larger in the HFrEF group $(3.3 \pm 0.4 \mathrm{kPa})$ compared to control $(1.0 \pm 0.2 \mathrm{kPa}, \mathrm{p}<0.001)$ and HFpEF patients $(1.3 \pm 0.2 \mathrm{kPa}, \mathrm{p}<0.05)$.

Table 1 Clinical characteristics of the HFrEF, HFpEF, and Control groups.

\begin{tabular}{lcccccc}
\hline Group & $\begin{array}{c}\text { DS pressure } \\
(\mathbf{m m H g})\end{array}$ & $\begin{array}{c}\text { ED pressure } \\
(\mathbf{m m H g})\end{array}$ & $\begin{array}{c}\text { DS volume index }(\mathbf{m L} / \\
\left.\mathbf{m}^{\mathbf{2}}\right)\end{array}$ & $\begin{array}{c}\text { ED volume index }(\mathbf{m L} / \\
\left.\mathbf{m}^{\mathbf{2}}\right)\end{array}$ & $\begin{array}{c}\text { Ejection fraction } \\
(\%)\end{array}$ & $\begin{array}{c}\text { LV mass index }(\mathbf{g} / \\
\left.\mathbf{m}^{\mathbf{2}}\right)\end{array}$ \\
\hline HFrEF & $15 \pm 3^{*}$ & $26 \pm 3^{*}$ & $127 \pm 11^{*} \neq$ & $147 \pm 10^{*} \neq$ & $24 \pm 3^{*} \neq$ & $123 \pm 7^{*}$ \\
HFpEF & $11 \pm 1 \dagger$ & $18 \pm 1 \dagger$ & $47 \pm 7$ & $59 \pm 6$ & $67 \pm 2$ & $95 \pm 14$ \\
Control & $6 \pm 1$ & $11 \pm 1$ & $48 \pm 2$ & $65 \pm 6$ & $59 \pm 3$ & $76 \pm 5$ \\
\hline
\end{tabular}

${ }^{*} p<0.05$ HFrEF vs. Control; $\nmid p<0.05$ HFpEF vs. Control; $\neq p<0.05$ HFpEF vs. HFrEF. Abbreviations: diastasis (DS), end-diastole (ED), left ventricle (LV). Volumes and masses indexed to body surface area.

${ }^{1}$ Auckland Bioengineering Institute, University of Auckland, Auckland, New

Zealand

Full list of author information is available at the end of the article 


\section{Conclusions}

Our findings suggest that personalized LV mechanical modeling may provide important diagnostic and therapeutic targets for HF management.

\section{Authors' details}

${ }^{1}$ Auckland Bioengineering Institute, University of Auckland, Auckland, New Zealand. ${ }^{2}$ Department of Engineering Science, University of Auckland, Auckland, New Zealand. ${ }^{3}$ The Heart Center, St Francis Hospital, Roslyn, NY, USA. ${ }^{4}$ Department of Anatomy with Radiology, University of Auckland, Auckland, New Zealand.

Published: 27 January 2016

doi:10.1186/1532-429X-18-S1-017

Cite this article as: Wang et al:: Quantifying passive myocardial stiffness and wall stress in heart failure patients using personalized ventricular mechanics. Journal of Cardiovascular Magnetic Resonance 2016

18(Suppl 1):017.

Submit your next manuscript to BioMed Central and take full advantage of:

- Convenient online submission

- Thorough peer review

- No space constraints or color figure charges

- Immediate publication on acceptance

- Inclusion in PubMed, CAS, Scopus and Google Scholar

- Research which is freely available for redistribution

Submit your manuscript at www.biomedcentral.com/submit
Ciomed Central 